\title{
Desenvolvimento de Currículo e Formação Docente no contexto da Educação Ambiental e Educação em Saúde
}

\author{
Curriculum Development and Teacher Training in the context of \\ Environmental and Health Education
}

\section{Desarrollo curricular y formación de profesores en el contexto de la educación ambiental y sanitaria}

\author{
Maria Cristina Pansera de Araújo (pansera@unijui.edu.br) \\ Universidade do Regional do Noroeste do Estado do Rio Grande do Sul - UNIJUí \\ Vidica Bianchi (vidica.bianchi@unijui.edu.br) \\ Universidade do Regional do Noroeste do Estado do Rio Grande do Sul - UNIJUí \\ Eva Teresinha de Oliveira Boff (evaboff@unijui.edu.br) \\ Universidade do Regional do Noroeste do Estado do Rio Grande do Sul - UNIJUí
}

\begin{abstract}
Resumo: A educação ambiental (EA) e em saúde (ES) são temáticas importantes no desenvolvimento de currículo e formação docente, pois possibilitam integração e contextualização de situações cotidianas relevantes para a vida. O objetivo foi identificar os indícios do desenvolvimento de currículo e da constituição do conhecimento de professor, na EA e ES, em dissertações e teses do Programa de Pós-Graduação em Educação nas Ciências (PPGEC-Unijuí). O estudo tem como base o referencial histórico-cultural, com sua centralidade em Vigotski (2013); Apple (2017), entre outros autores. A pesquisa é qualitativa documental, cuja análise é textual discursiva (MORAES; GALIAZZI, 2016). Foram identificadas 14 dissertações e 3 teses, no período 2010 a 2020, com os descritores EA e ES. Entre as dissertações, 9 abordaram ES (4 sobre Educação Alimentar e Nutricional, 3 sobre concepções de saúde e 2 sobre ES escolar); 3 sobre EA na Educação Básica; uma sobre as Questões Sociocientíficas e Socioambientais na formação docente; uma sobre o Ensino de Inglês com Storyline: The Neighborhood Environment and Health (Ambiente e Saúde da vizinhança), nos anos iniciais. As 3 teses analisaram EA e ES na formação de professores. As interações entre estes dois movimentos foram percebidas no material selecionado, indicando conhecimentos e estratégias produzidas na escola, na universidade e em grupos formativos.
\end{abstract}

Palavras-chave: Referencial Histórico-Cultural; Estado do conhecimento; Análise Textual Discursiva

Abstract: Environmental education (EE) and health education (HE) are important themes in the development of curriculum and teacher training, as they enable integration and contextualization of everyday situations relevant to life. The objective was to identify evidence of curriculum development and the constitution of teacher knowledge, in EE and HE, in dissertations and theses of the Postgraduate Program in Science Education (Unijuí).

Recebido em: 30/05/2021

Aceite em: 13/08/2021 
The study is based on the cultural historical framework with its centrality in Vigotski (2013); Apple (2017), among others authors. The research is qualitative documentary whose analysis is textual discursive (MORAES; GALIAZZI, 2016). Fourteen dissertations and three theses were identified, from 2010 to 2020, with the descriptors EA and HE. The research is qualitative documentary with discursive textual analysis (MORAES; GALIAZZI, 2016). Fourteen dissertations and three theses were identified, from 2010 to 2020, with the descriptors EE and HE. Nine dissertations addressed HE (four - Food and Nutrition Education; three - health concepts and two - school HE) and three EE in Basic Education; one, Socioscientific and Socioenvironmental Issues in teacher education; one, teaching English with Storyline: The Neighborhood Environment and Health in the early years. The three theses analyzed EE and HE in teacher education. The interactions between these two movements were perceived in the selected material, indicating knowledge and strategies produced at school, university and in training groups

Keywords: Historical-Cultural Reference; knowledge's state; discursive textual analysis

Resumen: La educación ambiental (EA) y la educación para la salud (ES) son temas importantes en el desarrollo del currículo y la formación docente, ya que permiten la integración y contextualización de situaciones cotidianas relevantes para la vida. El objetivo fue identificar evidencias del desarrollo curricular y la constitución del conocimiento docente, en EA y ES, en disertaciones y tesis del Programa de Posgrado en Educación Científica (PPGEC-Unijuí). El estudio se basa en el marco histórico-cultural con su centralidad en Vigotski (2013); Apple (2017), entre otros autores. La investigación es documental cualitativa con análisis textual discursivo (MORAES; GALIAZZI, 2016). Se identificaron catorce disertaciones y tres tesis, período 2010 a 2020, con los descriptores EA y ES. Nueve disertaciones abordaron ES (cuatro Educación Alimentaria y Nutricional; tres - conceptos de salud y dos - ES escolares); tres EA en Educación Básica; uno, Cuestiones sociocientíficas y socioambientales en la formación del profesorado; uno, enseñar inglés con Storyline: The Neighborhood Environment and Health, en los primeros años. Las tres tesis analizaron EA y ES en la formación del profesorado. Las interacciones entre estos dos movimientos se percibieron en el material seleccionado, indicando conocimientos y estrategias producidas en la escuela, la universidad y en los grupos de formación.

Palabras-clave: Referencia Histórico-Cultural; Estado del conocimiento; Análisis textual discursivo

\section{INTRODUÇÃO}

A educação pode promover a sensibilização das pessoas, para que todas estejam conscientes do valor do conhecimento e, dessa forma, usufruir criticamente os bens resultantes desse processo. Ainda, contribui para a conscientização social sobre as tecnologias

Recebido em: 30/05/2021

Aceite em: 13/08/2021 
desenvolvidas, as consequências e cuidados a serem tomados diante das inovações, tornando os campos da Educação Ambiental e Educação em Saúde focos de pesquisas.

Trata-se de abordá-las em suas múltiplas dimensões de ensino e aprendizagem, sobre os objetivos e princípios, os métodos e as técnicas, em espaços formais e não-formais, na ótica das distintas correntes pedagógicas, e na articulação de saberes curriculares, da experiência e da ação pedagógica (TARDIFF, 2002), na atuação autoral e autônoma do professor na produção do currículo.

Neste contexto, as temáticas Educação Ambiental (EA) e Educação em Saúde (ES) entrelaçam-se, no Desenvolvimento do Currículo e na Formação Docente, por meio da interação, integração, contextualização e discussão de situações concretas do cotidiano, tanto universitário quanto escolar, focalizadas em questões de relevância socioambiental e tecnocientífica. Por isso, é essencial reconhecer a Educação Ambiental (EA), como fundamento do sistema educacional (MORETTO et al, 2021), e das tendências, interesses e pontos de vista sobre as concepções de Educação em Saúde, na formação inicial e continuada de professores (SCHWINGEL; ARAÚJO, 2020), na perspectiva de formação crítica dos estudantes.

A compreensão da relação existente entre a sociedade humana e a natureza suscita muitos estudos sobre a qualidade de vida, o estado de saúde e de doença dos seres humanos, influenciados por fatores sociais e ambientais, bem como pelo atendimento das necessidades humanas na perspectiva do desenvolvimento sustentável (TRACANA, 2016).

Ao apresentar uma reflexão sobre Educação Ambiental, estudo do meio ambiente e internalização do conhecimento, Queiroz (2020) destaca:

a importância do diálogo interdisciplinar para construção de uma educação ambiental crítica na educação básica, levando em conta que o mundo contemporâneo é permeado por inúmeras contradições e conflitos que se apresentam na realidade vivida dos estudantes, consubstanciando temas sensíveis para o ensino escolar (p. 58).

No contexto universitário, a formação socioambiental, na vertente crítica da EA, pode fundamentar reflexões e ações emancipatórias, em âmbito individual e coletivo, na constituição de consciência sobre que relações devem ser adotadas para garantir uma vida de 
qualidade para todos os seres. Ao refletir sobre a (semi)formação na EA Universitária, Sudan e Zuin (2019) indicam que:

\begin{abstract}
As universidades, como lócus tradicionais de reflexões e produção de conhecimentos, pesquisa, ensino e extensão, possuem uma responsabilidade social diferenciada na busca por subsidiar a sociedade em teorias, reflexões críticas, pesquisas, inovações e experiências de Educação Ambiental e sustentabilidade. Entendemos que a universidade deve exercitar a sustentabilidade e buscar sua própria mudança valorizando a sua produção científica de forma a enraizá-la em seu próprio modo de funcionar. Permanece o desafio de manter e aprofundar reflexões e ações críticas, como resistência à semiformação nos processos de educação ambiental em universidades (p. 108).
\end{abstract}

A inclusão, no currículo, dos campos Educação Ambiental (SILVA; BALDIN, 2019) e Educação em Saúde (BOFF; ARAÚJO; CARVALHO, 2016) constitui uma discussão crucial na formação acadêmico-profissional e na Educação Básica (EB), independente da organização em disciplinas específicas, projetos interdisciplinares, sequências ou unidades didáticas, situação de estudo ou temática organizadora do currículo. Além disso, compreendemos que, nas escolhas das temáticas a serem desenvolvidas no currículo, o professor estabelece o seu conhecimento profissional (TARDIFF, 2002).

No que se refere às concepções de Educação e Saúde, muitos estudos foram realizados desde a década de 1950 (MARINHO; SILVA, 2013), relacionadas aos três termos: educação para a saúde, na saúde e em saúde. Educação em Saúde foi explicitada por Candeias (1997), Mohr (2002), Valadão (2004), Carvalho e Carvalho (2006), Pansera-de-Araújo, Emmel e Cambraia (2016), Cabral e Van der Sand (2016).

Considerando os argumentos dos autores enunciados, bem como o referencial histórico-cultural, com suas bases em Vigotski (2013), e a constituição do conhecimento de professor (TARDIFF, 2002), temos como objetivo identificar os indícios do desenvolvimento de currículo e da constituição do conhecimento de professor, na EA e ES, em dissertações e teses do Programa de Pós-Graduação em Educação nas Ciências (PPGEC-Unijuí).

De igual maneira, visamos a compreender se existe superação do distanciamento e da desarticulação entre o conhecimento de professor e o desenvolvimento de currículo, expressos nas teses e dissertações produzidas na Linha 1 - "Currículo e formação de professores" do PPGEC/Unijuí, no período de 2010 a 2020. 


\section{CAMINHOS METODOLÓGICOS}

A metodologia deste trabalho é de natureza qualitativa, na modalidade documental, sustentada em Lüdke e André (2016), que argumentam que o uso de documentos em investigações educacionais constitui uma técnica exploratória e que indica outras questões em conteúdos já analisados anteriormente.

A organização e sistematização dos dados está fundamentada nos argumentos de Moraes e Galiazzi (2016) sobre análise textual discursiva, um método rigoroso, no qual a interpretação dos pesquisadores carrega as concepções, os discursos e as ideias do investigador, ampliadas e reelaboradas durante o processo de construção do conhecimento. Com esta análise, identificamos as categorias temáticas nas dissertações e teses analisadas.

O estudo centrou-se na análise das teses e dissertações produzidas na Linha 1 Currículo e Formação de Professores - do Programa de Pós-Graduação em Educação nas Ciências (PPGEC), publicadas no repositório do Programa no período de 2010 a 2020. A busca ocorreu pelos descritores Educação Ambiental e Educação em Saúde, expressas no título, no resumo e/ou nas palavras-chave.

No total, 14 dissertações e 3 teses atenderam a estes critérios, sendo então organizadas em quadros temáticos com o título, autor e objetivos de cada produto e sua relação com a abordagem específica em cada campo.

\section{RESULTADOS}

Sobre Educação em Saúde, foram nove as dissertações que trataram doassunto, das quais quatro abordaram a Educação Alimentar e Nutricional (Quadro 1); três abordaram concepções e conceitos de saúde e corpo humano; e duas, sobre o estado do conhecimento da educação em saúde escolar.

\section{EDUCAÇÃO ALIMENTAR E NUTRICIONAL}

No quadro 1, são apresentadas as dissertações sobre educação alimentar e nutricional. 
Quadro 1 - Dissertações sobre educação alimentar e nutricional, período 2010-2020

\begin{tabular}{|c|c|c|}
\hline Autor e ano & Título & Objetivos \\
\hline $\begin{array}{lc}1 & \text { Jordana } \\
\text { Sartori }-2013\end{array}$ & $\begin{array}{l}\text { Estado da arte da pesquisa em } \\
\text { educação alimentar e nutricional }\end{array}$ & $\begin{array}{l}\text { Analisar a produção sobre "Educação Alimentar e } \\
\text { Nutricional", em artigos científicos, dissertações e } \\
\text { teses, publicados, de } 1990 \text { a 2010, na Scielo, na } \\
\text { Biblioteca Digital Brasileira de Teses e Dissertações } \\
\text { e no Portal da Capes. }\end{array}$ \\
\hline $\begin{array}{l}2 \text { Cláudia Thomé da } \\
\text { Rosa Piasetzki - } 214\end{array}$ & $\begin{array}{l}\text { Educação Alimentar e } \\
\text { Nutricional: Uma Temática } \\
\text { Constitutiva do Currículo } \\
\text { Escolar }\end{array}$ & $\begin{array}{l}\text { Analisar e compreender o processo de estudo sobre o } \\
\text { estado nutricional, hábitos alimentares e estilo de } \\
\text { vida de estudantes da educação básica, articulado } \\
\text { com a significação de conceitos disciplinares, } \\
\text { visando a produção de reflexões que contribuam } \\
\text { para uma melhor qualidade de vida. }\end{array}$ \\
\hline $\begin{array}{l}3 \text { Aline } \text { Bernard - } \\
2016\end{array}$ & $\begin{array}{l}\text { Promoção da Alimentação } \\
\text { Saudável no Contexto do } \\
\text { Currículo Escolar }\end{array}$ & $\begin{array}{l}\text { O objetivo geral da pesquisa é analisar criticamente } \\
\text { um processo de promoção da alimentação saudável, } \\
\text { na perspectiva de propiciar o desenvolvimento de } \\
\text { hábitos alimentares saudáveis, articulado aos } \\
\text { conteúdos do currículo escolar, tendo como base o } \\
\text { livro didático, as percepções da professora e dos } \\
\text { estudantes de uma turma da Educação Básica. }\end{array}$ \\
\hline $\begin{array}{l}4 \quad \text { Cristiane Tarine } \\
\text { Müller Girotto Reips - } \\
2019\end{array}$ & $\begin{array}{l}\text { Educação Alimentar e } \\
\text { Nutricional no Contexto da } \\
\text { Escola Especial: Implicações na } \\
\text { Formação Docente e na Saúde } \\
\text { dos Estudantes }\end{array}$ & $\begin{array}{l}\text { Identificar e analisar as implicações, na formação } \\
\text { docente e na saúde dos estudantes com necessidades } \\
\text { educacionais especiais, relacionadas a um processo } \\
\text { de Educação Alimentar e Nutricional, com foco na } \\
\text { promoção da saúde e no desenvolvimento cognitivo } \\
\text { dos sujeitos da pesquisa. }\end{array}$ \\
\hline
\end{tabular}

Fonte: Dados da pesquisa, 2021.

As dissertações que abordam o assunto Educação Alimentar e Nutricional (EAN) trataram do estado do conhecimento sobre estratégias EAN e do desenvolvimento de educação alimentar saudável no currículo escolar.

Para desenvolver o currículo, é indispensável conhecer o conteúdo, e o que ainda é necessário conhecer, para planejar e estabelecer estratégias que promovam a aprendizagem no decorrer das atividades de ensino, contribuindo para o desenvolvimento sociocognitivo e para uma vida saudável. As pesquisas sobre estado do conhecimento, por exemplo, estratégias de educação alimentar e nutricional ou de saúde na escola, possibilitam compreender aquilo que

Recebido em: 30/05/2021

Aceite em: 13/08/2021 
já foi realizado e o que ainda falta fazer, de modo a identificar questões pendentes e conteúdos a serem incorporados, no currículo.

Sartori (2013) analisou o conhecimento produzido de 1990 a 2010, em dissertações e teses sobre Educação Alimentar e Nutricional, avaliando a eficácia de estratégias relacionadas ao perfil nutricional, a práticas alimentares e índices de sobrepeso e obesidade. Nos textos, os autores expressaram preocupação com a autonomia dos sujeitos nas escolhas de alimentação e vida de qualidade. A organização das práticas, contudo, seguiam a racionalidade técnica instrumental, com distanciamento da realidade de vida da maioria dos grupos sociais envolvidos nos estudos sistematizados. As estratégias apresentadas nos textos selecionados pouco valorizavam o saber popular e as diferenças sociais e econômicas, deixando de dialogar com os sujeitos. A sistematização das publicações sobre EAN mostrou questões a serem melhor entendidas e novas perguntas de pesquisa a serem feitas. Nessa análise, ficou evidente a falta de informações quanto à formação de nutricionistas e professores de nutrição, bem como sobre quais os conteúdos essenciais menos abordados, propiciando um outro olhar para os currículos do curso de Nutrição. Além disso, a percepção de que a formação inicial do nutricionista deve incluir a função de educador, para ampliar a sua atuação nas redes de ensino e no atendimento aos grupos de reeducação alimentar.

Por outro lado, Piasetzki (2014) participou do desenvolvimento da Situação de Estudo (SE) "Nutrição e Qualidade de Vida", com os professores de uma escola pública, numa perspectiva problematizadora dos hábitos alimentares e estilo de vida dos estudantes, visando a mudanças alimentares e nutricionais com a significação de conceitos científicos. Com os dados referentes ao consumo alimentar, estado nutricional e prática de atividade física de uma turma de estudantes adolescentes de uma escola pública de Ensino Médio do Município de Ijuí, foi possível identificar os conceitos e o contexto de aprendizagem a ser utilizado.

A promoção da alimentação saudável, articulada ao currículo escolar, foi também abordada por Bernard (2016), ao evidenciar a necessidade de conhecer a realidade dos sujeitos para compreendê-la e, assim, contribuir na significação dos conceitos sobre a formação dos hábitos alimentares saudáveis. A pesquisa foi realizada com estudantes e professores de sete escolas do município de Porto Lucena, envolvendo 540 alunos na avaliação do estado nutricional. A partir deste diagnóstico, foi escolhida a escola que 
apresentou maior desvio nutricional (sobrepeso, obesidade, baixo peso) para a posterior discussão, com professores e alunos, sobre a importância de bons hábitos alimentares e as consequências para a saúde quando a alimentação é inadequada. A pesquisa mostrou profundo comprometimento da nutricionista/mestranda com a escola, que buscou também analisar os livros didáticos (LD) utilizados, para debater com os professores da escola sobre os aspectos não abordados na maioria dos LD, tais como: questões sociais, culturais, emocionais e disponibilidade de alimentos.

Ainda, no contexto escolar, a Educação Alimentar e Nutricional pode constituir uma temática do currículo, como Girotto (2019) afirma que:

As implicações das ações de EAN, na formação docente também foram positivas, pois a constituição do grupo interativo possibilitou às professoras discutirem com a nutricionista sobre temáticas relacionadas à alimentação e ao estado nutricional dos estudantes. Essas discussões permitiram momentos de reflexão quanto ao compromisso da escola e dos professores com a formação de hábitos alimentares saudáveis, principalmente com a saúde dos estudantes (p. 7).

As pesquisas de EAN, no desenvolvimento do currículo escolar, apontam que problematizar hábitos alimentares e estilo de vida dos estudantes fundamenta a conscientização quanto aos hábitos em relação à educação alimentar e nutricional e a significação dos conceitos científicos.

Isso remete às questões curriculares sustentadas na teoria crítica, cultural e sociológica, assumidas por Apple (2008) como centrais na educação sobre qual o conhecimento que pode ser considerado legítimo. Neste sentido, a EAN torna-se motivo para o desenvolvimento dos conteúdos curriculares quando a intencionalidade do professor é a inter-relação, a autorreflexão e a reflexão social, como afirma o autor:

\footnotetext{
Nossa tarefa é ensinar e aprender; levar nossas indagações tão a sério quanto o tema requer; e receber as críticas que nos fazem respeitosa e abertamente; desejá-las mesmo, para que também possamos ser convocados a questionar nosso próprio senso comum, da mesma forma que pedimos aos outros (APPLE, 2008, p. 55).
}

Muitas vezes, a falta de aproximação entre o conhecimento cotidiano e o currículo formal impede que surjam novas situações e temas, não previstos nem planejados, mas que 
são essenciais para que a aprendizagem seja internalizada, na mediação de outros (VIGOTSKI, 2013). Ao desenvolver o currículo, a partir de temáticas relacionados à EAN, diferentes situações podem emergir e trazer à tona um conjunto de saberes que tornam este conhecimento significativo. Sacristán (2017, p. 58) discorre que "o currículo define um território prático que pode ser discutido, investigado, mas, acima de tudo, sobre o qual intervir".

No que se refere à escola, a constituição de grupos com profissionais de diferentes áreas do conhecimento, que discutam e desenvolvam ações de EAN, implica na reflexão e produção de conhecimento do professor qualificado sobre os hábitos alimentares, de modo a incentivar escolhas alimentares saudáveis. Estes grupos podem promover diálogos interdisciplinares significativos para a formação conceitual crítica dos jovens estudantes, como propõe. Thiesen (2008):

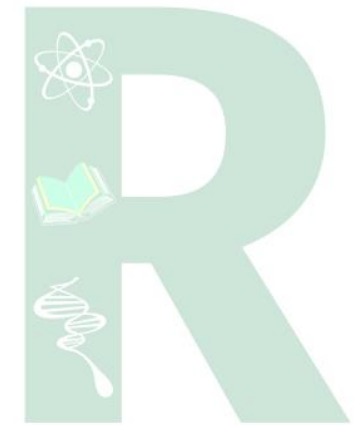

\begin{abstract}
como fenômeno gnosiológico e metodológico, está impulsionando transformações no pensar e no agir humanos em diferentes sentidos. Retoma, aos poucos, o caráter de interdependência e interatividade existente entre as coisas e as ideias, resgata a visão de contexto da realidade, demonstra que vivemos numa grande rede ou teia de interações complexas e recupera a tese de que todos os conceitos e teorias estão conectados entre si. Ajuda a compreender que os indivíduos não aprendem apenas usando a razão, o intelecto, mas também a intuição, as sensações, as emoções e os sentimentos (p. 552).
\end{abstract}

A interação entre família e escola é formadora de crianças, de jovens e dos próprios professores, o que pode incrementar a elaboração de estratégias educacionais, que auxiliem nos questionamentos, esclarecimentos e tomadas de decisão quanto às mudanças de hábitos para uma vida de qualidade.

\title{
EDUCAÇÃO EM SAÚDE: CONCEPÇÕES, CONCEITOS E CORPO
}

\section{HUMANO}

Quanto ao tema Educação em Saúde (Quadro 2), foram quatro as dissertações que abordaram as concepções e os conceitos de saúde de estudantes universitários iniciantes e do 
curso técnico em enfermagem. Duas abordaram o estado do conhecimento de práticas de educação em saúde na escola, analisadas com a Epistemologia de Fleck.

Quadro 2 - Dissertações de educação em Saúde, 2010-2020

\begin{tabular}{|c|c|c|}
\hline Autor e ano & Título & Objetivos \\
\hline $\begin{array}{l}1 \text { Daiane Thaise } \\
\text { Faber }-2010\end{array}$ & $\begin{array}{l}\text { Concepções de Universitários da } \\
\text { Área de Saúde Sobre Biologia, } \\
\text { Saúde Reprodutiva e Tabagismo }\end{array}$ & $\begin{array}{l}\text { Avaliar as concepções de universitários } \\
\text { iniciantes sobre tabagismo e seu efeito na } \\
\text { biologia e saúde reprodutiva de homens e } \\
\text { mulheres. }\end{array}$ \\
\hline $\begin{array}{l}2 \text { Carine } \\
\text { Magalhaes Zanchi } \\
\text { de Mattos - } 2010\end{array}$ & $\begin{array}{l}\text { Processo de Significação } \\
\text { Conceitual de Práticas de } \\
\text { Enfermagem em Curso Técnico: } \\
\text { Perspectiva Histórico-Cultural }\end{array}$ & $\begin{array}{l}\text { Analisar o processo de ensino e } \\
\text { aprendizagem desde a evolução dos } \\
\text { conceitos e interações em sala de aula, na } \\
\text { constituição do profissional enfermeiro } \\
\text { docente, nas reflexões sobre o preparo } \\
\text { pedagógico. }\end{array}$ \\
\hline $\begin{array}{l}3 \text { Tatiane Cristina } \\
\text { Possel Greter } \\
\text { Schwingel }-2016\end{array}$ & $\begin{array}{l}\text { Estilos e Coletivos de Pensamento } \\
\text { das Pesquisas de Educação em } \\
\text { Saúde na Escola (2005 a 2015) }\end{array}$ & $\begin{array}{l}\text { Analisar o tema Educação em Saúde (ES) na } \\
\text { escola, em periódicos e programas de Pós- } \\
\text { Graduação indexados na Scielo e no Portal } \\
\text { da Capes, de } 2005 \text { a } 2015 \text {, e as contribuições } \\
\text { dos autores para identificar os estilos e } \\
\text { coletivos de pensamento advindos do estudo } \\
\text { do tema. }\end{array}$ \\
\hline $\begin{array}{l}4 \text { Rosangela } \\
\text { Daniela Freitag de } \\
\text { Andrade - } 2016\end{array}$ & $\begin{array}{l}\text { Processo de Significação dos } \\
\text { Conceitos de Ciências da Natureza } \\
\text { no Contexto de Situação de Estudo }\end{array}$ & $\begin{array}{l}\text { Analisar a elaboração e desenvolvimento de } \\
\text { três Situações de Estudo numa escola de } \\
\text { Educação Básica de Três Passos, na } \\
\text { perspectiva de compreender a evolução da } \\
\text { significação conceitual de conteúdos sobre o } \\
\text { corpo humano. }\end{array}$ \\
\hline $\begin{array}{l}5 \text { Ana Paula Dutra } \\
-2017\end{array}$ & $\begin{array}{l}\text { Relações entre Coletivos de } \\
\text { Pensamento na Educação em } \\
\text { Saúde Escolar e Ensino de } \\
\text { Ciências em Eventos da Área }\end{array}$ & $\begin{array}{l}\text { Analisar artigos sobre Educação em Saúde, } \\
\text { (1997 a 2015), em anais de eventos } \\
\text { nacionais, de pesquisa em Ensino de } \\
\text { Ciências, para identificar círculos esotéricos, } \\
\text { exotéricos, ver formativo, circulação intra e } \\
\text { intercoletiva de ideias, estilos e coletivos de } \\
\text { pensamento propostos por Ludwig Fleck, dos } \\
\text { autores dos textos selecionados. }\end{array}$ \\
\hline
\end{tabular}

Fonte: Dados da Pesquisa, 2021.

Faber (2010) avaliou a compreensão de universitários da Universidade Federal de Santa Maria-RS, recém-egressos da educação básica, matriculados no segundo semestre de 2008 nos cursos de farmácia, fisioterapia, medicina e odontologia, sobre tabagismo e seu efeito na biologia e saúde reprodutiva de homens e mulheres. Dos 14 estudantes que alguma vez experimentaram o tabaco, 11 são de pais tabagistas, o que sugere a importância da família na 
formação de hábitos. Esse tipo de pesquisa acaba produzindo novas compreensões e questionamentos sobre os conteúdos relativos às drogadições e educação sexual no currículo escolar.

Mattos (2010) filmou suas aulas no curso técnico de enfermagem e, após a transcrição das filmagens, realizou a análise microgenética das interações produzidas para as aprendizagens dos estudantes e constituição do seu conhecimento de professor.

Os estudos de estado de conhecimento das práticas de educação em saúde na escola e dos coletivos e estilos de pensamento e os diálogos inter e intracoletivos dos autores foram realizados por Schwingel (2016) e Dutra (2016), que identificaram estratégias na forma de oficinas e minicursos, muitas vezes realizados em outros horários que não os da sala de aula. Foi possível perceber a articulação e os marcos teóricos da temática, tanto nas dissertações e teses quanto nos textos de anais de eventos, mostrando a constituição de coletivos e estilos de pensamento da área.

Por fim, na dissertação "Processo de Significação dos Conceitos de Ciências da Natureza no Contexto de Situação de Estudo", Andrade (2016) abordou a elaboração e desenvolvimento de três situações de estudo (SE) sobre o corpo humano, com alunos do oitavo ano da educação básica, de modo a contextualizar as características morfofisiológicas e ambientais visando a qualidade de vida. $\mathrm{O}$ envolvimento dos estudantes na produção e desenvolvimento das SEs propiciou a evolução da compreensão conceitual sobre a temática.

\section{EDUCAÇÃO AMBIENTAL E QUESTÕES SOCIOCIENTÍFICAS}

Quanto à Educação Ambiental e Questões Sociocientíficas (Quadro 3), três estudos discorreram sobre o tema na Educação Básica; uma quarta dissertação abordou as Questões Sociocientíficas e Socioambientais na formação docente; e uma outra, sobre Ensino de Inglês no Desenvolvimento da Storyline: The Neighborhood Environment and Health (Ambiente e Saúde da vizinhança):

Quadro 3 - Dissertações sobre educação ambiental e questões sociocientíficas (2010 a 2020)

\begin{tabular}{|l|l|l} 
Autor e ano & Título & Objetivos
\end{tabular}

Recebido em: 30/05/2021

Aceite em: 13/08/2021 


\begin{tabular}{|c|c|c|}
\hline $\begin{array}{l}1 \text { Rosângela Inês } \\
\text { Matos Uhmann - } 2011\end{array}$ & $\begin{array}{l}\text { Estratégias de Ensino e } \\
\text { Interações em Aulas de Física } \\
\text { e Química no Ensino Médio } \\
\text { Com Foco na Educação } \\
\text { Ambiental }\end{array}$ & $\begin{array}{l}\text { Integrar a EA no ensino de física, para significação e } \\
\text { articulação conceitual das formas de energia usadas e } \\
\text { alternativas para transcender os conceitos escolares, } \\
\text { no contexto para intervir no mundo material. }\end{array}$ \\
\hline $\begin{array}{l}2 \text { Natalia Katherine } \\
\text { Garcia Ramirez - } 2016\end{array}$ & $\begin{array}{l}\text { Produção de Significados por } \\
\text { Professores de Ciências sobre } \\
\text { Currículo Centrado em } \\
\text { Questões Sociocientíficas: } \\
\text { Contribuições para a } \\
\text { Formação do Professor } \\
\text { Pesquisador }\end{array}$ & $\begin{array}{l}\text { Analisar significados e sentidos construídos por } \\
\text { professores acerca do currículo escolar focado em } \\
\text { Questões Sociocientíficas e Socioambientais na } \\
\text { perspectiva Histórico-Cultural, nos registros escritos, } \\
\text { produzidos na pesquisa denominada "Programa } \\
\text { Colombo-brasileiro de formação de professores de } \\
\text { Ciências na interface universidade-escola". }\end{array}$ \\
\hline $\begin{array}{l}3 \text { Jamile Tábata } \\
\text { Balestrin Konageski - } \\
2018\end{array}$ & $\begin{array}{l}\text { Storyline no Ensino de Língua } \\
\text { Inglesa Nos Anos Iniciais da } \\
\text { Educação Básica }\end{array}$ & $\begin{array}{l}\text { Analisar a aprendizagem de língua inglesa pelos } \\
\text { estudantes dos Anos Iniciais do Ensino Fundamental, } \\
\text { com base na Abordagem Storyline; investigar a } \\
\text { relação teoria e prática na análise de uma unidade } \\
\text { temática, fundamentada na Abordagem Storyline. }\end{array}$ \\
\hline $\begin{array}{l}4 \text { Aline Giovana } \\
\text { Finger - } 2019\end{array}$ & $\begin{array}{l}\text { Significação dos Conceitos de } \\
\text { Ecologia na Perspectiva de } \\
\text { Tomada de Consciência sobre } \\
\text { os Problemas Ambientais }\end{array}$ & $\begin{array}{l}\text { Investigar os conhecimentos cotidianos dos } \\
\text { estudantes e problematizá-los, na perspectiva de } \\
\text { ampliação dos significados; desenvolver o Protocolo } \\
\text { de Avaliação Rápida de Ambiente (PAR) na visita a } \\
\text { um riacho; analisar o processo de investigação } \\
\text { instituído. }\end{array}$ \\
\hline $\begin{array}{l}5 \text { Marciele Dias Santos } \\
\text { Cabeleira - } 2020\end{array}$ & $\begin{array}{l}\text { A Educação Ambiental como } \\
\text { Articuladora de Teorias e } \\
\text { Práticas no Processo de } \\
\text { Produção do Currículo Escolar }\end{array}$ & $\begin{array}{l}\text { Analisar a contribuição de práticas pedagógicas sobre } \\
\text { questões de EA, na perspectiva de desenvolvimento } \\
\text { do currículo para formação de sujeitos críticos e } \\
\text { responsáveis em relação ao ambiente. }\end{array}$ \\
\hline \multicolumn{3}{|c|}{ Fonte: Dados da Pesquisa, 2021.} \\
\hline
\end{tabular}

na premissa de que devemos educar crianças e jovens para que se tornem adultos responsáveis em relação ao meio em que vivem. Quanto a essa perspectiva, porém, há controvérsias, em razão de que alguns autores consideram que as mudanças devem ser buscadas e ensinadas aos adultos atuais, para que possamos garantir um mundo saudável e sustentável para todos.

Uma delas salienta o entrelaçamento da EA, no ensino de Ciências da Natureza e suas Tecnologias, ao focar criticamente os conteúdos, com participação ativa dos estudantes. Esta interação corrobora o entendimento de que os sujeitos são constituídos pela mediação das relações, que ocorrem ao longo das práticas sociais. A significação de conceitos científicos, também, é salientada numa dissertação que demonstra a relação entre o desenvolvimento do currículo e a formação docente. 
A forte interação entre desenvolvimento do currículo e a formação docente é desvelada na medida em que se atribui significado ao que se ensina. No caminhar da profissão como docente, a formação inicial e continuada, quando tratada a partir de temáticas que organizam o currículo, propõem reflexões sobre a prática e a organização da teoria, como processo essencial para a constituição docente. Segundo Freire (2001), a formação não acontece num único momento, pois "esta atividade exige que sua preparação, sua capacitação, sua formação se tornem processos permanentes" (p. 28).

As Questões Sociocientíficas e Socioambientais na formação docente foram tratadas por Ramirez (2016), numa investigação sobre os significados atribuídos por professores de Ciências sobre o tema no Currículo. A proposição de projetos de pesquisa na escola, em articulação com docentes da Universidade, propicia o desenvolvimento de práticas reflexivas e colaboram de forma ativa e constante na reconstrução do próprio currículo. Neste sentido, professores passaram a entender a importância do trabalho cooperativo para a melhoria de sua prática e dos processos formativos dos estudantes.

O ensino de inglês no desenvolvimento da Storyline: The Neighborhood Environment and Health (Ambiente e Saúde da vizinhança) foi organizado considerando os dois temas simultaneamente, no ensino integrado de uma língua estrangeira e conteúdos escolares. Com a perspectiva histórico-cultural (VIGOTSKI, 2013) sobre a aprendizagem e o desenvolvimento da linguagem e da cognição, a relação entre teoria e prática foi investigada numa unidade temática estudada por alunos do $2^{\circ}$ Ano dos Anos Iniciais do Ensino Fundamental. Esta abordagem propiciou identificar a aprendizagem dos conceitos escolares e da língua estrangeira.

As teses selecionadas ocuparam-se em investigar grupos formativos de professores em formação inicial e continuada em Educação Ambiental e em Saúde (Quadro 4).

Quadro 4 - Teses de Educação Ambiental e em Saúde (2010 a 2020)

\begin{tabular}{|l|l|l|}
\hline \multicolumn{1}{|c|}{ Autor e ano } & \multicolumn{1}{|c|}{ Título } & \multicolumn{1}{c|}{ Objetivos } \\
\hline $\begin{array}{l}1 \text { Eliane } \\
\text { Gonçalves dos } \\
\text { Santos }-2019\end{array}$ & $\begin{array}{l}\text { A Educação em Saúde nos Processos } \\
\text { Formativos de Professores de Ciências } \\
\text { da Natureza mediada por Filmes }\end{array}$ & $\begin{array}{l}\text { Investigar implicações decorrentes de um } \\
\text { processo formativo de professores de Ciências } \\
\text { da Natureza, mediado pelo uso de filmes } \\
\text { comerciais, para a constituição de aprendizagens } \\
\text { de uma visão ampliada de Educação em Saúde. }\end{array}$ \\
\hline
\end{tabular}

Recebido em: 30/05/2021

Aceite em: 13/08/2021 


\begin{tabular}{|l|l|l|}
\hline $\begin{array}{l}\text { L Lezita Zalamena } \\
\text { Schmitt - 2020 }\end{array}$ & $\begin{array}{l}\text { O Desafio de Inserir a Pesquisa sobre } \\
\text { Problemas da Realidade Socioambiental } \\
\text { como Prática Curricular Integradora do } \\
\text { Conhecimento Escolar no Ensino } \\
\text { Médio }\end{array}$ & $\begin{array}{l}\text { Compreender situações limites da realidade, pela } \\
\text { pesquisa como princípio pedagógico } \\
\text { mobilizador de processos de integração } \\
\text { curricular na produção de um conhecimento } \\
\text { escolar com significado, no Ensino Médio, } \\
\text { entendendo que outro mundo é possível de ser } \\
\text { criado, como propulsor do desenvolvimento } \\
\text { humano/social. }\end{array}$ \\
\hline $\begin{array}{l}\text { Possel Greter } \\
\text { Schwingel }-2020\end{array}$ & $\begin{array}{l}\text { Potencialidade de Grupos Formativos } \\
\text { para a Constituição Profissional } \\
\text { Docente: Compreensões de Educação } \\
\text { em Saúde Articuladas ao Currículo } \\
\text { Escolar }\end{array}$ & $\begin{array}{l}\text { Analisar as compreensões sobre educação em } \\
\text { saúde, expressas por professores em processo de } \\
\text { formação inicial e continuada e suas estratégias } \\
\text { promotoras de saúde, articuladas ao currículo } \\
\text { escolar e à constituição profissional docente. }\end{array}$ \\
\hline
\end{tabular}

Fonte: Dados da Pesquisa, 2021.

Santos (2019) identificou três categorias na análise dos episódios, produzidos na transcrição das vídeogravações dos encontros formativos com licenciandos do Pibid e professores da educação básica e da universidade: i) evolução das compreensões de Saúde e Educação em Saúde, no diálogo com professores no grupo colaborativo; ii) filmes comerciais como instrumento de reflexões sobre questões curriculares no processo formativo; iii) produção do conhecimento científico. Os resultados obtidos propiciaram o reconhecimento das implicações decorrentes das interações dos professores em formação inicial e continuada, no grupo de trabalho colaborativo, em que um novo conhecimento pedagógico do conteúdo de saúde foi desenvolvido, possibilitando nova organização curricular.

Schwingel (2020) pesquisou o campo da educação em saúde (ES) e suas interfaces, no currículo escolar e formação de professores, a partir de compreensões e estratégias promotoras de saúde, expressas por professores em processo de formação inicial e continuada, no currículo escolar e constituição profissional docente.

Schmitt (2020) analisou a inserção da pesquisa sobre problemas da realidade na formação e prática de professores, numa perspectiva integradora do currículo, no contexto do Ensino Médio. E, investigou as contribuições do processo de estudo, planejamento e ação coletivamente desenvolvidos na escola acerca do uso abusivo de agrotóxicos, na integração curricular, para posterior compreensão conceitual dos professores e estudantes. 
De algum modo, é possível identificar indícios de que o desenvolvimento do currículo e a constituição do conhecimento de professor são estabelecidos no contexto organizativo da Educação Ambiental e Educação em Saúde.

\section{CONSIDERAÇÕES FINAIS}

A análise das dissertações e teses produzidas na Linha 1 "Currículo e Formação de Professores", do PPGEC, no período de 2010 a 2020, mostra fortes indícios do desenvolvimento de currículo, que se articulam com a construção do conhecimento de professor, em relação à educação em saúde e à educação ambiental. O maior número de trabalhos versou sobre educação em saúde, mostrando maior efetividade do Programa Saúde na Escola, visto que diversos trabalhos abordam ações sistemáticas no ambiente escolar. Embora a educação ambiental seja trabalhada em todas as escolas, ainda mostra a existência de ações pontuais, a exemplo de trabalhos desenvolvidos na semana do meio ambiente. Da análise emergiram três categorias: Educação em Saúde: Concepções, Conceitos e Corpo Humano; Educação Ambiental; Questões Sociocientíficas.

Assim, esta análise permitiu identificar aproximações e inovações produzidas nas pesquisas, mostrando a articulação do desenvolvimento de currículo com a formação docente, em que o professor, ao planejar e efetivar o currículo nas suas aulas, constitui o conhecimento pedagógico, tecnológico e didático do conteúdo, que, por sua vez, imprime um outro olhar sobre o processo formativo desencadeado, que repercute na elaboração e planejamento do currículo.

\section{REFERÊNCIAS}

APPLE, W. M. A educação pode mudar a sociedade? Petrópolis, RJ: Vozes, 2017.

APPLE, M. W.; BURAS, K. L. Currículo, poder e lutas educacionais: com a palavra, os subalternos. Porto Alegre: Artmed, 2008.

BOFF, E. T. de O.; ARAÚJO, M. C. P. de; CARVALHO, G. S. de (orgs). Interações entre Conhecimentos, Valores e Práticas na Educação em Saúde. Ijuí: Editora Unijuí, p. 109 132. 2016.

Recebido em: 30/05/2021

Aceite em: 13/08/2021 
CABRAL, F. B.; VAN DER SAND, I. C. P. Educação para a Saúde. Diálogos nos diferentes cenários de práticas educativas. Ijuí- RS: Editora Unijuí, 2016.

CANDEIAS, N. M. F. Conceitos de educação e de promoção em saúde: mudanças individuais e mudanças organizacionais. Revista de Saúde Pública, v. 2, n. 31, p. 209-213, 1997.

CARVALHO, G. S.; CARVALHO, A. A. S. Educação para a saúde: Conceitos, práticas e necessidades de formação. Um estudo sobre as práticas de educação para a saúde, dos enfermeiros. Lisboa: Editora: Lusociencia, 2006.

FREIRE, P. Carta de Paulo Freire aos professores. Estudos Avançados, São Paulo, v. 15, n. 42, p. 259-268, ago. 2001.

GIROTTO, C. T. M. Educação alimentar e nutricional no contexto da escola especial: implicações na formação docente e na saúde dos estudantes. Ijuí, 2019. 130 f. Dissertação (Mestrado) - Universidade Regional do Noroeste do Estado do Rio Grande do Sul (Campus Ijuí). Educação nas Ciências. 2019.

MARINHO, Júlio Cesar Bresolin, SILVA, João Alberto da. Conceituação da educação em saúde e suas implicações nas práticas escolares. Ensino, Saúde e Ambiente, v. 6, n. 3, p. 21 38, dez. 2013.

MOHR, A. A natureza da Educação em Saúde no ensino fundamental e os professores de ciências. 2002. 406 f. Tese Doutorado (Educação). Centro de Ciências da Educação, Universidade Federal de Santa Catarina, SC. 2002.

MORAES, R.; GALLIAZZI, M. do C. Análise textual discursiva. Ijuí: Editora Unijuí, 2016.

MORETTO, R.; LIMA, J.; GUIDORZI, M.; AFFONSO, H. Formação de Professores e Educação Ambiental: desafios e conquistas no contexto imposto pela Pandemia de Covid19. Revista Insignare Scientia - RIS, v. 4, n. 3, p. 291-308, 3 mar. 2021.

PANSERA-DE-ARAÚJO, M. C., EMMEL, R.; CAMBRAIA, A. C. Aproximações e distanciamentos dos currículos de Ciências Biológicas e Computação: um espaço tempo para educação em saúde. In: BOFF, E. T. de O.; ARAÚJO, M. C. P. de; CARVALHO, G. S. de (orgs). Interações entre Conhecimentos, Valores e Práticas na Educação em Saúde. Ijuí: Editora Unijuí, p. 109 -132, 2016.

QUEIROZ, R. J. de G. Educação Ambiental, estudo do meio e internalização do conhecimento. Rev. Eletrônica do Mestrado em Educação Ambiental, Rio Grande, v. 37, n. 4, p. 44-60, set./dez. 2020.

SACRISTÁN, G. J. El currículum como estudio del contenido de la enseñanza. In: SACRISTÁN, G. J. et al. Ensayos sobre el currículum: Teoría e Prática. São Paulo: Cortez; Madrid: Ediciones Morata, p. 29-62, 2017.

SILVA, Amanda Carina Leal; BALDIN, Nelma. Ambientalização curricular do Ensino Superior na Universidade da Região de Joinville - Univille: os cursos de Licenciatura e Direito. Revista Contexto \& Educação, v. 34, n. 107, p. 52-71, 2019.

SUDAN, D. C.; ZUIN, V. G. A (Semi)formação na Educação Ambiental Universitária: tensionamentos a partir de um estudo empírico sob a ótica da Teoria Crítica. Revista Pesquisa em Educação Ambiental, v. 14, n. 2, 2019.

Recebido em: 30/05/2021

Aceite em: 13/08/2021 
TARDIF, M. Saberes docentes e formação profissional. Petrópolis: Vozes, 2002.

THIESEN, J. dos S. A Interdisciplinaridade como um movimento articulador no processo de ensino-aprendizagem. Revista Brasileira de Educação, v. 13, n. 39, set./dez. 2008.

TRACANA, Rosa Branca. Educação Ambiental e a Saúde: conhecimentos, valores e práticas da poluição em manuais escolares de 16 países. p. 181-200. In: BOFF, E. T. O.; ARAÚJO, M. C. P.; CARVALHO, G. S. (orgs.). Interações entre conhecimentos, valores e práticas na educação em saúde. Ijuí: Editora Unijuí, p. 204, 2016.

SCHWINGEL, T.; ARAÚJO, M. Compreensões de educação em saúde na formação inicial e continuada de professores. Revista Insignare Scientia - RIS, v. 3, n. 2, p. 368-385, 25 ago. 2020 .

VALADÃO. M. M. Saúde na escola: um campo em busca de espaço na agenda intersetorial. 2004. 154 p. Tese (Doutorado). Departamento de Prática de Saúde Pública. Universidade de São Paulo, SP, 2004.

VENTURI, T.; MOHR, A. Análise da Educação em Saúde nos Parâmetros Curriculares Nacionais a partir de uma nova perspectiva. In: ENCONTRO NACIONAL DE PESQUISA EM EDUCAÇÃO EM CIÊNCIAS - ENPEC, 9., 2013, São Paulo. Atas [...]. Disponível em: http://www.nutes.ufrj.br/abrapec/ixenpec/atas/listaresumos.htm. Acesso em: 19 de Junho de 2016

VIGOTSKI, L. S. A construção do pensamento e da linguagem. São Paulo: Martins Fontes, 2013.

WORLD HEALTH ASSOCIATION. Ottawa charter for health promotion. In: AN INTERNATIONAL CONFERENCE ON HEALTH PROMOTION. Ottawa, 1986.

Recebido em: 30/05/2021

Aceite em: 13/08/2021 